\title{
Automatic Control System for Bodies of Revolution Processing
}

\author{
Oleg I. Drachev ${ }^{1, a^{*}}$, Boris M. Gorshkov ${ }^{2, b}$ and Natalia S. Samokhina ${ }^{2, c}$ \\ ${ }^{1}$ Togliatti State University, Togliatti, Russia \\ ${ }^{2}$ Volga Region State University of Service, Togliatti, Russia

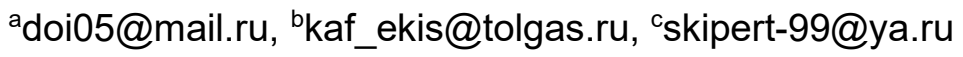

\begin{abstract}
Keywords: Metalworking Processing of Bodies, Self-Centering Steady Rests, Automatic Control System, Manufacturing Non-Rigid Shaft-Type Parts, Level of Residual Stresses
\end{abstract}

\begin{abstract}
This research is related to metalworking processing of bodies of revolution with the help of universal lathe machines. The technology includes the application of two types of vibrations to the working tool and the processed surface error measurement. To increase the manufacturing accuracy, the workpiece processed surface error is measured while a workpiece is being rotated; this rotation is performed with the workpiece being rigidly fixed in end supports and at the same time being damped in the sections between these supports. Furthermore, the parameters of vibrations applied to the tool working travel are defined by the workpiece form error and the nature of distribution of stresses that appear when the workpiece is fixed; the nature of the workpiece processed surface form error is extrapolated from the data obtained in the workpiece sections between the supports. Before manufacturing, the workpiece is corrected while being fixed in rigid supports, and the correction itself is performed as the function of magnitude and vector of the workpiece maximum deflection plane. The workpiece may be fixed in rigid supports; steady rests with double rollers may be used as such supports. The workpiece dampening in its sections between end supports may be performed using self-centering steady rests.
\end{abstract}

\section{Introduction}

Non-rigid shaft-type vital parts are used in modern-day mechanical engineering, machine tool engineering and instrument engineering. The continuous increase of their production volume is induced by the improvement of strength calculations and designs, by the constant decrease of the products' metal intensity and by the increase of high-speed precision machines production.

Imbalances in the design parameters of non-rigid bodies of revolution (NRBR) create serious technological difficulties in the production process; the main reasons for these difficulties are the following:

a) significant elastic and plastic deformations at all stages of the parts' processing, assembly and operation;

b) low vibration resistance and various types of pliancy of the technological system elements;

c) significant influence of technological heredity on the performance reliability;

d) workpieces distortion caused by uneven residual stresses added at all the stages of processing;

e) the parts' low thermal resistance.

The negative effect of the above-mentioned factors during the production of non-rigid bodies of revolution leads to the technological bases dysfunctions, the parts' form and size errors, surface defects, cutting modes limitations and, ultimately, to the decrease of operation accuracy and reliability [1-15]. 


\section{Relevance and goal of this research}

The known methods of manufacturing axisymmetric bodies of revolution according to the traditional technology using standard steady rests are not efficient for manufacturing non-rigid shaft-type parts. At the present moment the matter of producing these types of parts is solved through the selection of processing modes and the application of manual correction operations, which do not ensure the required product quality. The improvement of technological processes of the NRBR mechanical processing is an important goal that increases the production efficiency and the mechanical engineering products quality. The goal of our research is to increase the accuracy of processing, to maintain it after processing and to obtain the following technical results: to increase the accuracy of the part form in cross-section by stabilizing the cutting force during the workpiece rotation, to increase the stability of the part geometry over time by forming a more uniform pattern of stress distribution throughout the workpiece volume. The use of an automatic control system simplifies the error measurement due to the application of the method of extrapolating the measured signals in the sections under the steady rests. The controlled steady rests decrease the vibrations level in the cutting zone.

\section{Automatic control system}

This article focuses on the automatic control system (ACS) of the technological processing system in lathes for bodies of revolution of non-rigid parts. The ACS operates as follows. A shaft workpiece (Fig.1) is fixed in supports 1; depending on the process pressure in drive 2 (Fig.2) of the clamp, these supports can operate in two modes: damper mode or rigid supports mode.

Intermediate supports act as dampers 3. Two end supports act as rigid supports 4 . The shaft is rotated the required number of times at low speed. The sensor system 5 (Fig.2), which is installed on the body 6 of supports 1, measures the displacement of levers 7 (changes of gap clearances S2, S3) and of rod 8 (change of gap clearance S1) of supports 1 under the influence of profile errors (workpiece surface wobbling against the bases - two end steady rests acting as rigid supports; and deviation from the out-of-roundness in the cross-section); the obtained data is processed in control unit 9.

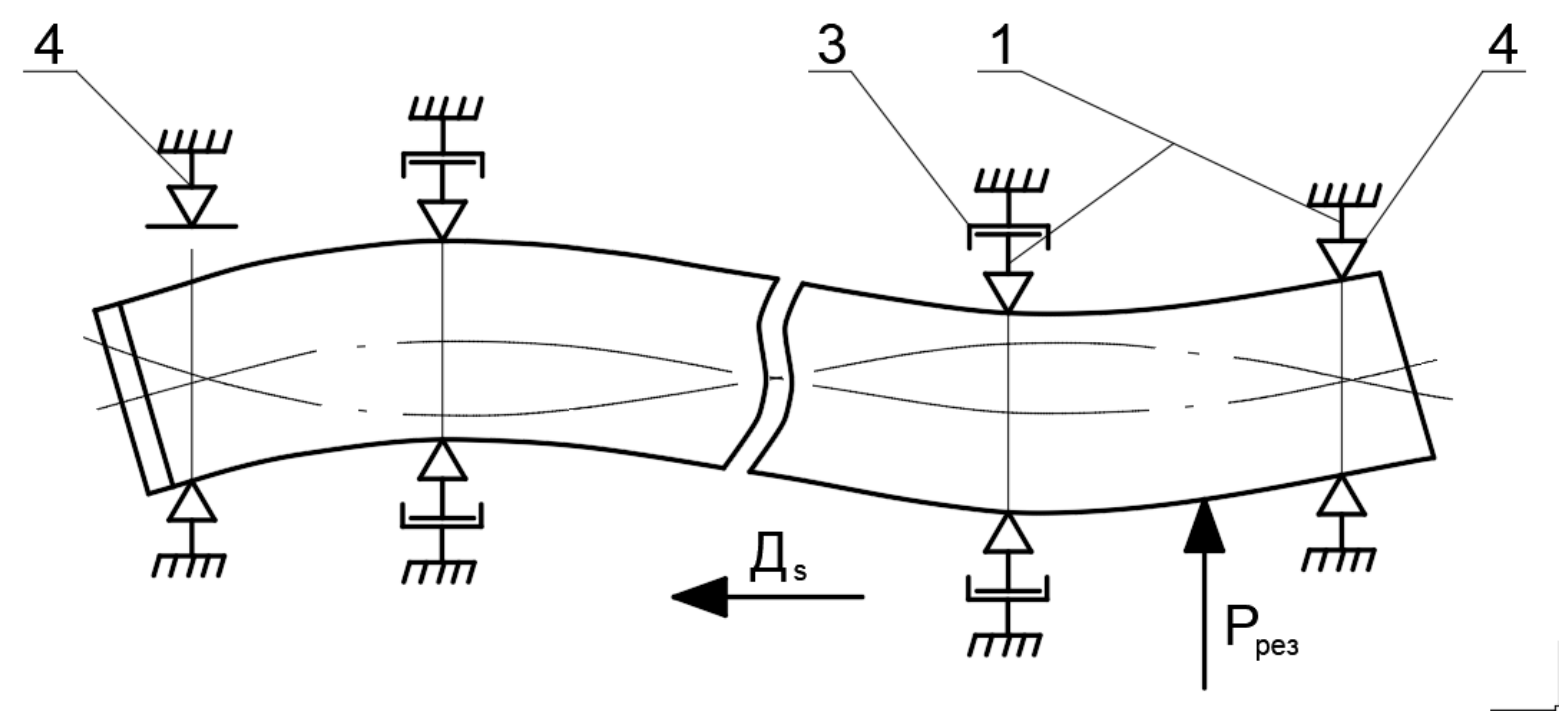

Fig. 1. Shaft installation diagram for error measurement. 


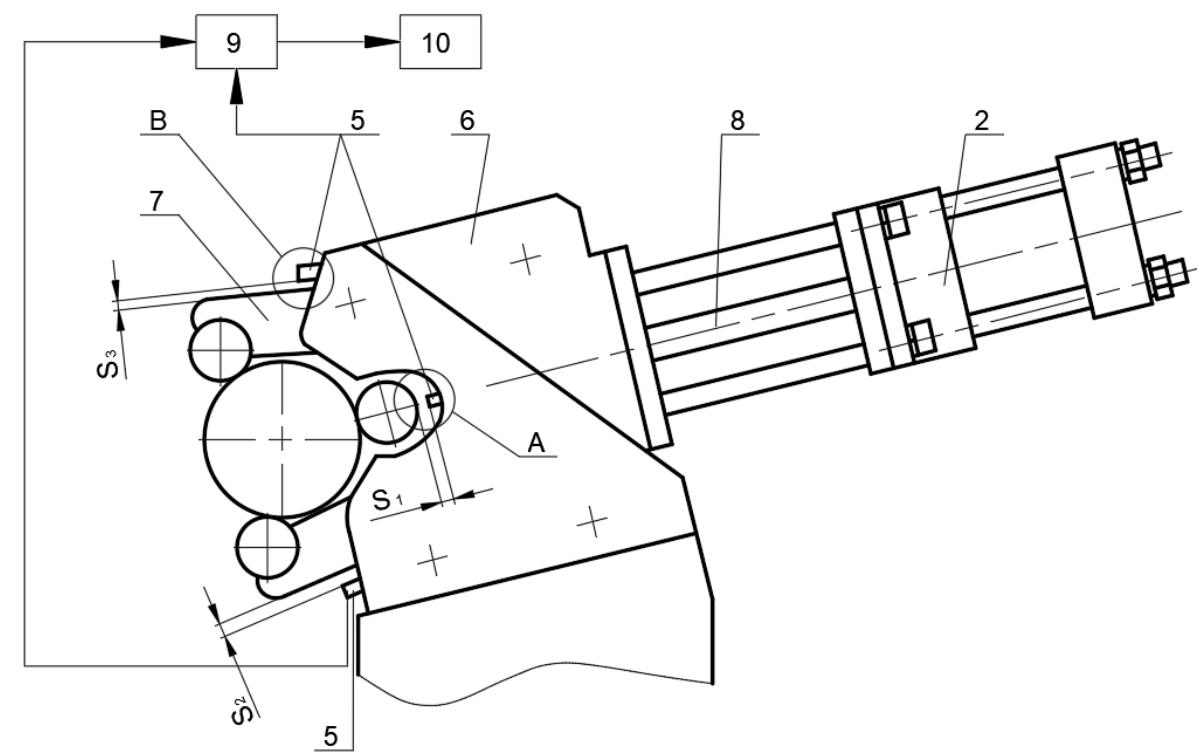

a)

Fig. 2. a-General view of a steady rest with a measuring system, $b$ and $c$-location of sensors.

A harmonic analysis of the obtained information is carried out to identify the first and second harmonics of vibrations of the workpiece profile errors. A general picture of the spatial attitude of the processed surface in relation to the base necks under the steady rests (working in the rigid supports mode) and its profile is formed in control unit 9. The nature of the error location in the workpiece sections between the steady rests is determined by extrapolating the data obtained in the sections of the steady rests installation, because the cutting pattern is strictly regular in the longitudinal direction (along the axis along the helix line with a certain pitch). The data is transmitted from control unit 9 to feed drives input 10, the change of feed Ds (Fig.1) is set during the turning process in order to control the cutting force (to stabilize it) as a function of the predicted allowance change. To stabilize the workpiece axis during the manufacturing process, supports 1 are sequentially switched into the rigid supports mode along the workpiece length as the cutting zone moves, so that it is always located between rigid supports 4 . The tool is assigned with vibrations with two components. One of them is determined by spatial deviations, the second one is determined by the nature of the stress state in the workpiece volume. Taking into account the spatial errors (Fig.3), the first component of the tool vibrations is set (its form is $\Delta \mathrm{f}$ and its location is e). 


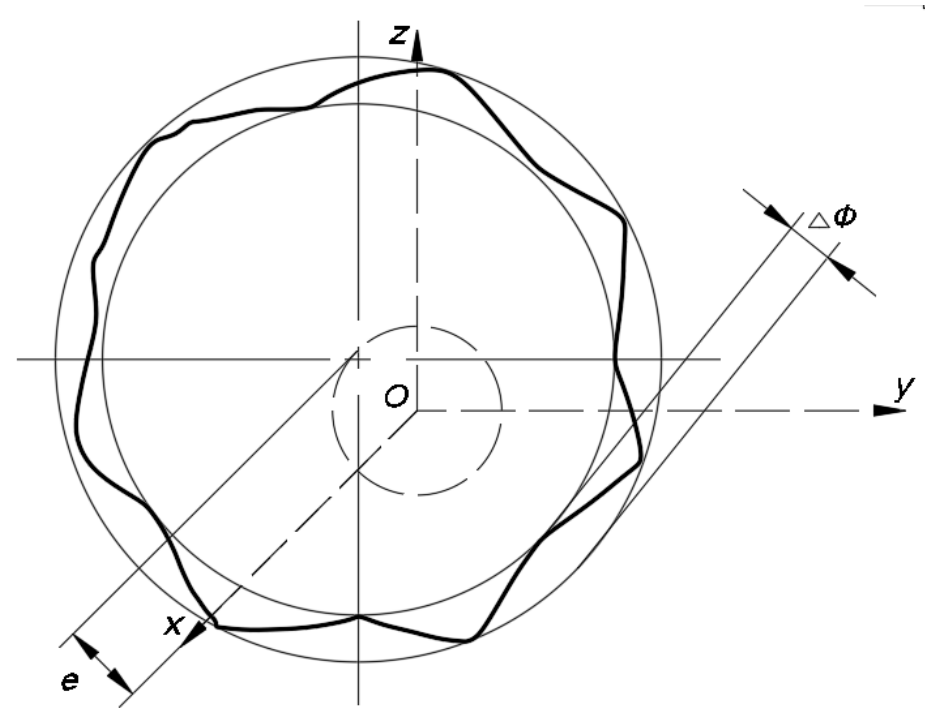

Fig. 3. View of the errors of bodies of revolution.

Furthermore, the feed control is carried out as a function of the cutting force stabilization (when the allowance is increased, the feed is decreased and vice versa). When a workpiece is clamped, the deflection of its axis leads to the formation of stresses in the workpiece volume (compression stress on the convex side and tension stress on the concave side). Once the workpiece is released, these tensions lead to the workpiece distortion. The second component is applied during the manufacturing process in order to equalize these stresses. To balance the residual stresses, the feed value is reduced in the workpiece part with the residual tension stresses and is increased in the part with the compression stresses, thus equalizing the stress state along the workpiece cross-section.

The tool vibrations may be reduced if a workpiece is processed preliminarily. Before a shaft is processed with the dressing roll installed into the support, it is processed in the midspans to equalize the stress state in the workpiece volume and to decrease the spatial deviations by bending the shaft in the direction that is opposite to the maximum deflection and that lies in its plane. This way we form the stresses opposite to the stresses appearing when a workpiece is clamped. To compensate the plastic deformations, a shaft workpiece is deformed during the manufacturing process with these deformations taken into account: it is bended by a certain value.

The number of supports 1 (Fig.1) and their location along the workpiece length depend on the function of its length and diameter, taking into consideration that the ratio of the span length to the workpiece diameter is no more than 5 . The end steady rests have double rollers (not shown) in order to increase the reactive torque when the workpiece is rotated and to stabilize its axis.

\section{Research}

The development of adaptive control systems, including in particular the ACS for the workpiecesupport subsystem, is a radical method of increasing vibration resistance and accuracy.

To assess the effectiveness of the ACS, we carried out the experiments to determine the value of the nonuniformity of the residual stresses that exist in a workpiece and appear in it after the turning process.

The goal of our experiment was to ascertain the reason why the shaft bending changes during the machining process. Our task was to determine what influences the shaft form the most: the residual stresses in the workpiece or the stresses that appear during the turning process. 
For this experiment we used the samples made of steel of austenite class $12 \mathrm{X} 18 \mathrm{H} 10 \mathrm{~T}$. The 1500 mm long samples were cut from a supplied bar with the diameter of $30 \mathrm{~mm}$. These samples were divided into two batches, 12 pieces in a batch. Each batch was processed in its own mode:

The 1st batch: supplied material. The lathe with the ACS was used for turning: cutting depth $\mathrm{t}$ $=0.5-0.75 \mathrm{~mm}$, the part's rotation speed $\pi=800 \mathrm{rpm}$, tool advance $\mathrm{S}=0.063 \mathrm{~mm}$ per rotation. We used carbide tools with carbide material VK13, with the cutting edge angle $\alpha=450$. The sample warping was measured after each pass.

The 2nd batch: full annealing of all 12 samples was performed (heating up to the temperature of $1060^{\circ} \mathrm{C}$, holding for 2-3 hours, cooling in the furnace, the samples were hung vertically); therefore, the residual stresses in the workpieces were eliminated or nominal. The parts' warping was measured before and after the samples' annealing. Then the samples were processed like those from the 1 st batch.

The value of the deflection of a part's axis was taken as a measure of a part's warping (axial mode changes); this value was measured in a vertical position in five sections with the help of dial gauges with the graduation mark of $0.01 \mathrm{~mm}$, the results were entered into a table. The deflections were measured immediately after the treatment process and after a period of time up to 240 hours in order to determine if there was the relaxation of stresses after the treatment.

The experiment's results were used to create the graphs of changes of the samples' deflections as the samples were turned; Fig.4a shows the results of the 1st batch processing, the supplied material samples; Fig. $4 \mathrm{~b}$ shows the results of the 2 nd batch processing, the annealed samples. Lines of different configuration represent the samples with various serial numbers (1...6).

Both graphs show that the shaft form during the treatment process is not stable; the deflection tends to appear during the following treatment. This phenomenon is more noticeable when one looks at the unannealed samples. The shaft deflection decreases down to $0.4 \ldots 0.6 \mathrm{~mm}$ (for the unannealed samples) and down to $0.2 \ldots 0.4 \mathrm{~mm}$ (for the annealed samples) during the turning process (in the beginning, with removal $\mathrm{t}=1 \ldots .2 \mathrm{~mm}$ ).

Therefore, we can make a conclusion that there are residual stresses present in a workpiece. These stresses amount to $40 \%$ of the stresses in the unannealed samples.

During further turning the shaft form becomes even less stable and the deflection value increases.

Beside that, the graphs show that the samples, both annealed and unannealed, that have a small deflection in their initial state have a lesser deflection during the machining process. The initially straight samples may provide a deflection close to the allowable one: $0.01 . .0 .04 \mathrm{~mm}$ per one meter of the shaft length.

We should also note that there exists the residual stresses relaxation: over time the deflection change ranges widely, from 0 to $100 \%$, but in average it is $13 \ldots 24 \%$.

Let us define the value of the nonuniformity of the residual stresses in the test sample using the above-mentioned theoretical calculations. The shaft deflection with the ratio $1 / \mathrm{d}-50$ is $0.5 \mathrm{~mm}$ in average in our experiments. This corresponds to the residual stresses nonuniformity of $20 \%$ with their minimal value ores $=100 \mathrm{~N} / \mathrm{mm} 2$. The nonuniformity value should be even less with the residual stresses minimal value ores $=20.30,100 \mathrm{~N} / \mathrm{mm} 2$.

Additionally, we carried out the experiments with and without the use of the ACS with the following cutting modes: $\pi=1440 \mathrm{rpm}, \mathrm{S}=0.11-0.22 \mathrm{~mm}$ per rotation; without the ACS: two passes with cutting depth $\mathrm{t} 1=1.5 \mathrm{~mm}, \mathrm{t} 2=2.8 \mathrm{~mm}$; with the ACS: one pass with cutting depth $\mathrm{t} 3$ $=3 \mathrm{~mm}$. Cutter material is T15K6. This experiment allowed us to obtain roughness $\mathrm{Ra} 0.8$, to increase the longitudinal accuracy up to $10 \mu \mathrm{m} / \mathrm{m}$ with the diameters range of $30-60 \mathrm{~mm}$ and the 
lengths range of $1.5-4 \mathrm{~m}$ and to eliminate the finished product residual deformations during operation.

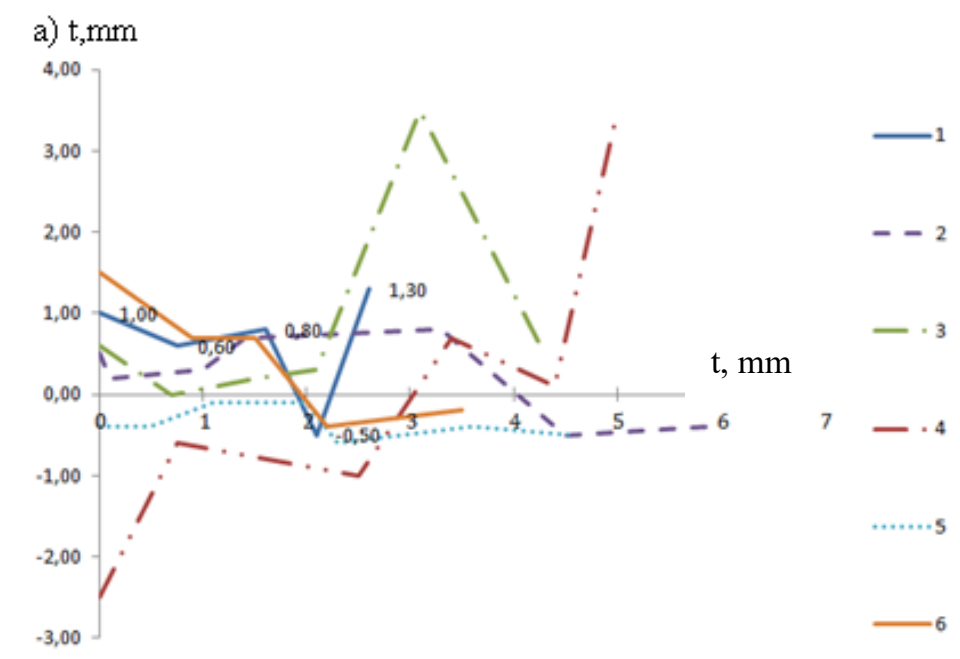

b) t,mm

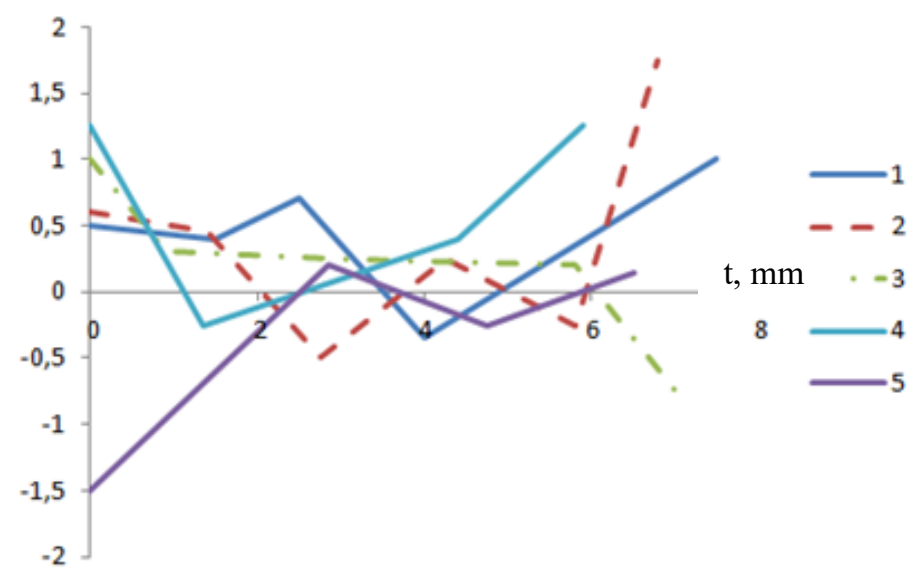

Fig. 4. Measurements of the samples' deflections during the turning process:

$a$-supplied material samples, $b$-annealed samples.

\section{Conclusion}

The experiments we carried out prove beyond all doubt that it is necessary to control the course of the technical process, ranging from the correct operation to the thermal power processing and the finishing. Only by decreasing the level of the residual stresses and equalizing them along the entire workpiece length we can keep the processes of relaxation and creeping to a minimum, i.e. we can stabilize the finished part form for the entire period of operation.

\section{References}

[1] Solomentsev Y.M., Mitrofanov V.G., Protopopov S.P. and others. Adaptive process control. Moscow: Mashinostroenie, 1980. 
[2] Drachev O.I. Manufacturing techniques for low-stiff axisymmetric parts. Saint Petersburg: Politekhnika, 2005.

[3] Drachev O.I. \&Kravtsov A.N. Automatic control of the process of low-stiff parts turning. Togliatti: VSTU, ZAO «ONIKS», 2012.

[4] Artamonov E.V., Tveryakov A.M., Shtin A.S. Definition of the temperature of the ultimate operational capability of instrumental hard alloys. Obrabotkametallov (tekhnologia, oborudovanie, instrumenty) - Metals processing (Technology, Equipment, Tools), vol. 20 (2018) 47-57.

[5] Bobrowski A.V., Drachev O.I., Gorshkov B.M. Improving the operational accuracy of shafts by volumetric plastic deformation. Available online, 2020.

https://doi.org/10.1016/j.matpr.2020.01.458

[6] Zakovorotniy V.L., Voloshin D.A., Rodriges S.B., Flek M.B. Method of modeling elastic deformations of cylindrical end mills in the process of milling. Investigation of machines and tools for machining complex and precise surfaces. Saratov: SSTU, 2003.

[7] Vladimirov A.A. \&Sergiev A.P. Influence of vibrational amplitude on component functions of the complex vibrational effect of low-frequency vibrations. IzvestiyaVolgGTU - The Bulletin of VolgGTU, 7 (2018) 13-17.

[8] Zakovorotniy V.L., Ladnik I.V., Dhande S.G. A method for characterization of machinetools dynamic parameters for diagnostic purposes. Journal of Materials Processing Technology, vol. 53, 1995. https://doi.org/10.1016/0924-0136(94)01745-M

[9] Zakovorotniy V.L. \&Bordatchev E.V. Computer aided system for analysis of the cutting motion nonunformity during machine tool approval tests. Modelling, Measurement and Control B, AMSE Press, vol. 56 (3), 1994.

[10] Bobrovsky A. V., Drachev O.I., Kravtsov A.P. Improving the accuracy and quality of machining by controlling the cutting process, IOP Conference Series: Materials Science and Engineering 709 (2020) 044088. https://doi.org/10.1088/1757-899X/709/4/044088

[11] Palagnyuk G.G. Theoretical substantiation of the method of reducing the energy intensity of the cutting process and its multiparameter active control. Diagnostics and control in technical systems (1995) $74-82$.

[12] Starkov V.K. Machining, stability and quality management in automated production. Moscow: Mashinostroenie, 1989

[13] Chemavskiy F.G. Modern trends in the construction of precast cutters with non-reversible plates, Review. Moscow: NIIMash, 1983

[14] Savilov A.V., Svinin V.M., Timofeev S.A. Investigation of output parameters of titanium reverse turning. Journal of Physics: Conference Series. International Conference "Information Technologies in Business and Industry” 2018 - Enterprise Information Systems. https://doi.org/10.1088/1742-6596/1015/4/042055

[15] Svinin V.M., Samsonov A., Savilov A.V., Pyatykh A. (2018). Self-oscillation suppression when turning non-rigid shafts using spring tools and the spring headstock center. MATEC Web of Conferences, vol. 224 (2018) 01059. https://doi.org/10.1051/matecconf/201822401059 